\title{
SOBRE ORGULHO, VERGONHA E SUPERAÇÃO: O IMPACTO DA CORRUPÇÃO NA DOTAÇÃO DE SENTIDO AO TRABALHO ENTRE OS FUNCIONÁRIOS DA PETROBRAS
}

\author{
ABOUT PRIDE, SHAME AND OVERCOMING: THE IMPACT OF CORRUPTION ON THE \\ MEANING OF WORK AMONG PETROBRAS' EMPLOYEES.
}

Recebido em 04.12.2017. Aprovado em 20.12.2017 Avaliado pelo sistema double blind review

\author{
Daniel Oswaldo Santana de Souza \\ dossouza@gmail.com \\ Pontifícia Universidade Católica do Rio de Janeiro (IAG/PUC-Rio) - Rio de Janeiro - RJ
}

\begin{abstract}
Resumo
Nos últimos dois anos o Brasil vê o desenrolar de uma operação policial que atingiu em cheio a principal empresa estatal do país. Chamada de "Lava Jato", as investigações capitaneadas pela Polícia Federal tinham como objetivo inicial desbaratar esquemas de lavagem de dinheiro envolvendo lobistas, empresários e políticos brasileiros. Não levou muito tempo até que as investigações chegassem à Petrobras, onde foram denunciadas diversas ações fraudulentas de pagamento de propinas através de empresas fantasmas, "laranjas", visando ao financiamento de campanhas políticas, acordos de favorecimento e enriquecimento ilícito de seus agentes. Neste cenário específico, os aspectos subjetivos relacionados ao trabalho dos funcionários da Petrobras merecem atenção. Pesquisas acerca do significado do trabalho multiplicam-se no meio acadêmico, reforçando a relevância que a dotação de sentido à atividade profissional tem tanto no desempenho dos funcionários, como no das organizações como um todo (ROSSO, DEKAS e WRZESNIEWSKI, 2010). Esta pesquisa, através de entrevistas em profundidade com empregados da estatal, investigou o impacto da percepção da corrupção no significado do trabalho, de acordo com a definição tridimensional do modelo teórico proposto pelo MOW (1987). Pelas declarações coletadas, percebe-se que a segunda dimensão do construto - a que trata das normas sociais, sobre direitos e deveres relacionados ao trabalho do indivíduo para com a empresa e a sociedade - foi a mais impactada, principalmente no que se refere aos deveres dos profissionais para com a empresa e a sociedade. As outras dimensões - centralidade e objetivos e resultados valorizados do trabalho - foram influenciadas em menor grau.
\end{abstract}

Palavras-chaves: Corrupção; Significado do trabalho; Subjetividade; Petrobras; Lava Jato.

\section{Abstract}

On the last two years, Brazil has been watching the development of a police operation that hit deeply country's biggest State company. Called "Lava Jato" (CarWash), these investigations headed by the Federal Police intended to disarticulate money laundering schemes involving lobbists, businessmen and Brazilian politics. It did not take a long time until the investigations led to Petrobras. There, several fraud actions regarding the payment of bribe to shell corporations, in order to finance political campaigns, to close illicit deals and illicit enrichment were denounced. On this specific scenario, subjective aspects concerning work among Petrobras' employees deserve attention. Research about the meaning of work flourish on the academic field, ratifying the relevance of the subject, and its impact, not only on employee's performance, but also on organization's general results (ROSSO, DEKAS e WRZESNIEWSKI, 2010). This article, through in-depth interviews with the Petrobras' employees, analyzed the impact of the perception of corruption on the meaning of work, as it is proposed, tridimensionally, by the MOW Team (1987). By employees' narrative, it could be noticed that the second dimension of the meaning of work concept - regarding social norms, 
obligations and entitlements employees feel they have with the company and society - was deeply affected, mostly on the obligations employees feel they have with Petrobras and the Brazilian Society. Other dimensions - work centrality and desired work outcomes - were lightly affected.

Keywords: Corruption; Meaning of work; Subjectivity; Petrobras; Lava Jato.

\section{Introdução}

Nos últimos dois anos o Brasil vê o desenrolar de uma operação policial que atingiu em cheio a principal empresa estatal do país. Chamada de "Lava Jato", as investigações capitaneadas pela Polícia Federal tinham como objetivo inicial desbaratar esquemas de lavagem de dinheiro envolvendo lobistas, empresários e políticos brasileiros. Não levou muito tempo até que as investigações chegassem à Petrobras, onde foram denunciadas diversas ações fraudulentas de pagamento de propinas através de empresas fantasmas, "laranjas", visando ao financiamento de campanhas políticas, acordos de favorecimento e enriquecimento ilícito de seus agentes.

Amplamente acompanhada pela imprensa nacional - e até a internacional - o desenrolar das fases da operação ganha ares de trama de ficção, onde diversos personagens ganham notoriedade, sejam do Poder Judiciário, da esfera política ou do empresariado brasileiro. $O$ forte apelo popular insuflado por essa ampla cobertura jornalística conseguiu cativar a atenção de determinados setores da sociedade brasileira, que acompanham passionalmente - ora idolatrando, ora execrando esses "personagens" - 0 desmantelamento de diversos esquemas de corrupção que impactavam diretamente no desempenho da maior empresa do país.

Ao longo dos seus 63 anos de existência, a Petrobras construiu sua reputação com base em ideias de pioneirismo, tecnologia e pesquisa, servindo como um motivo de orgulho para os brasileiros e consolidandose como uma carreira dos sonhos para profissionais de diversas áreas. Todavia, com a evolução da Lava Jato, a estatal enfrenta uma complicada situação no que tange à sua imagem. Seu quadro efetivo com mais de 78 mil funcionários também acompanha o avançar das investigações pela imprensa e sente de perto as suas consequências, tanto dentro, quanto fora da empresa.

Neste cenário específico, os aspectos subjetivos relacionados ao trabalho dos funcionários da Petrobras merecem atenção. Trabalhos acerca do significado do trabalho multiplicam-se no meio acadêmico, reforçando a relevância que a dotação de sentido à atividade profissional tem tanto no desempenho dos funcionários, como no das organizações como um todo (ROSSO, DEKAS e WRZESNIEWSKI, 2010).

Este trabalho tem como objetivo investigar de que maneira as denúncias de corrupção envolvendo a Petrobras impactam a dotação de sentido ao trabalho dentre seus empregados. Nesse intuito, tomando como referência o construto tridimensional do significado do trabalho, proposto pelo Meaning of Work International Research Team (MOW, 1987), foram realizadas entrevistas em profundidade com sete funcionários da estatal. A seguir, o texto prossegue com um referencial teórico sobre corrupção e significado do trabalho, os aspectos metodológicos da pesquisa, a apresentação dos resultados e se encerra com algumas conclusões e a discussão de limitações e propostas de pesquisas futuras.

\section{Referencial Teórico}

\section{Corrupção}

Com base em levantamento feito no banco de dados da Scientific Periodicals Electronic Library (Spell), as pesquisas acerca do fenômeno da corrupção aprofundaram-se nos últimos 20 anos na literatura científica nacional. Trabalhos que objetivavam uma definição conceitual do construto, as consequências da corrupção, assim como propostas de instrumentos de mensuração e controle ocuparam as mentes de diversos pesquisadores, que trataram do tema em variados campos, tanto na esfera privada, quanto na esfera pública.

Silva (1994) chama a atenção para a ausência de uma definição funcional da corrupção entre meados da década de 1980 e início da década de 1990, quando o país, após o período de exceção, iniciava a discutir 


\section{SOBRE ORGULHO, VERGONHA E SUPERAÇÃO: O IMPACTO DA CORRUPÇÃO NA DOTAÇÃO DE SENTIDO AO TRABALHO ENTRE OS FUNCIONÁRIOS DA PETROBRAS}

os casos de corrupção, que na época começavam a ser publicizados através da imprensa. Neste sentido, tem-se a corrupção como um "tipo de desvio de um padrão de conduta institucionalizado que se caracteriza principalmente pela utilização do público pelo privado com um manifesto propósito de favorecimento pessoal ou grupal". Por essa perspectiva, tem-se três categorias de análise: social, política e econômica. A primeira faz referência a existência de grupos com interesses divergentes, numa relação desequilibrada de poder público (traficantes $X$ policiais, por exemplo). A segunda resultaria diretamente em benefícios estritamente políticos (nepotismo, tráfico de influência, financiamento ilegal de campanhas eleitorais, por exemplo). A última tem a ver com a utilização do público pelo privado, na intenção de gerar benefícios financeiros imediatos (suborno e peculato, por exemplo).

Apesar dessa definição funcional do fenômeno, o ato corrupto per se era tido como algo difícil de se conceituar. Brei (1996a) atribui tal dificuldade ao fato da discussão em torno do tema acontecer até então ainda num estágio pré-paradigmático. Ao analisar a prática da corrupção através de quatro perspectivas distintas - mercado, público, regulamentações formais e opinião pública - o autor (1996b) conclui reafirmando a dificuldade de um consenso conceitual, ocasionado pela moralidade relacionada à avaliação de um ato como corrupto, ou não. A tentativa de atribuir sentido à realidade passaria não só por um filtro individual, mas social, ressaltando a complexidade da análise da ação corrupta. Apesar da ciência de tal fato relacionado ao fenômeno, o autor, referenciando trabalhos anteriores, consegue listar algumas causas -relacionadas à natureza humana, fatores sociais, culturais, econômicos, políticos, ou até à ineficácia de sistemas públicos de gestão - e soluções - que iriam desde punições pontuais, até ações de intervenção sistemáticas e estruturadas.

No caso do Brasil, a corrupção é considerada como um fenômeno institucional (SILVA, 1999). Tanto sua ocorrência, quanto a percepção de sua ilegalidade e a possibilidade de controle dependem do grau de evolução institucional do país, como argumenta Silva (1999), em sua análise através do viés econômico do fenômeno. Ou seja: instituições nacionais bem consolidadas - tais como órgãos jurídicos e legislativos competentes, por exemplo - podem determinar como as práticas corruptas acontecem, são percebidas publicamente e podem ou não ser passíveis de punição. Tais práticas geram custos não apenas às organizações, mas à sociedade como um todo, como afirma 0 autor.

As consequências da corrupção são objeto de pesquisa de diversos estudos. Silva et al. (2009) afirmam que a corrupção atinge diretamente o caráter transparente da gestão pública. Isso faz com que estejam em risco a manutenção da estabilidade política, social e econômica de um país. Vaz e Rocha (2005) destacam os impactos na imagem institucional - tal como um processo de deterioração - causados pelas denúncias e investigações de casos de corrupção. Carvalho (2009), por sua vez, aponta que tais fatos intensificam a repressão financeira, afastando empresas de fontes formais de recursos - acesso a crédito bancário, por exemplo - o que muitas vezes redunda numa desaceleração de projetos de investimento.

Miari et al. (2015) sublinham os efeitos da corrupção junto aos acionistas. De acordo com os autores, o mercado acionário brasileiro responderia de forma ineficiente à corrupção organizacional, uma vez que tais atos poderiam ser percebidos como que em prol da organização. Em consonância à pesquisa de Anand, Ashforth e Joshi (2005, apud MIARI et al., 2015), os sujeitos seriam capazes de criar estratégias mentais a fim de justificar suas práticas corruptas. Dessa maneira, uma vez que elas resultam em vantagens para a organização e, consequentemente, para os acionistas, o mercado permaneceria isento da responsabilidade de punir ou coibir tais ações.

A fim de evitar tais adversidades, medidas de controle e mensuração da corrupção vem sido discutidas cientificamente. Oliveira (2006) sublinha a importância do controle externo, interno e de sistemas de contabilidade, na composição de um "trinômio integrado e perfeito", como uma medida eficiente no combate à corrupção. Costa (2008) investiga a eficiência de códigos de conduta de responsabilidade social no controle e prevenção de práticas corruptas. Ainda nesse sentido, Silva et al. (2009) defendem que o trabalho da auditoria precisa ser aprofundado e holístico - para além do âmbito contábil - a fim de tornar-se uma ferramenta eficaz no combate à corrupção. 
A transparência das contas públicas (TCP) é apontada por Rausch e Soares (2010) como uma significativa inibidora de atos corruptos. Dessa forma, salientando a capacidade de agência social, os pesquisadores defendem que através da TCP, o Estado estaria mais próximo da sociedade, estabelecendo uma relação mais interativa e clara. Zuccolotto e Teixeira (2014) ratificam tal raciocínio ao relacionarem 0 desenvolvimento democrático à ação de institutos supremos de auditoria e poderes legislativos eficientes. Países que apresentam tal configuração apresentariam positivos índices de transparência fiscal, impactando a percepção - e consequentemente prevenção e punição - da corrupção.

Neste corpo teórico, não foram identificadas pesquisas que articulassem o fenômeno da corrupção a aspectos subjetivos e individuais relacionados à experiência profissional. Tal fato evidencia 0 caráter exploratório e a relevância desta pesquisa. 0 referencial teórico continua com uma explanação sobre 0 construto do significado do trabalho.

\section{Significado do Trabalho}

Direcionando-se para além de uma suposta obviedade para uma definição do construto "significado do trabalho", muitos pesquisadores em todo o mundo propuseram perspectivas distintas acerca do tema (BRIEF e NORD, 1990; MOW International Research Team, 1987; SUPER e SVERKO, 1995, CAVALHEIRO, 2010; TOLFO et al. 2011). Nesta seção, pretende-se introduzir um panorama da produção científica relacionada ao assunto, passando por sua mais recente revisão de literatura ROSSO, DEKAS e WRZESNIEWSKI, 2010). Em seguida, destaca-se a proposta tridimensional postulada pela equipe do MOW (1987), que serve de base teórica para esta pesquisa.

As expressões significado e sentido do trabalho têm sido alvo de discussão no meio acadêmico (TOLFO et al. 2005): ora "sentido" é utilizado para se referir a experiência subjetiva do indivíduo no trabalho, ora é "significado". Tolfo e Piccinini (2007) argumentam que as duas podem ser utilizadas como sinônimas uma da outra. A base para essa argumentação está na estrutura etimológica dos termos e tal abordagem será seguida neste artigo.

De acordo com pesquisadores de comportamento organizacional que concentram suas análises em perspectivas psicológicas, as bases da construção do significado do trabalho partiriam de subjetividades individuais resultantes da vivência profissional (BAUMEISTER, 1991; BRIEF e NORD, 1990; WRZESNIEWSKI, 2003). Muitos pesquisadores se debruçaram sobre o tema. Dessa variedade científica argumenta-se que o construto sentido do trabalho ainda carece de estruturas generalistas, que possibilitem sua maior integração, consistência e compreensão (ROSSO, DEKAS e WRZESNIEWSKI, 2010). No sentido de estabelecer certa unidade a esse corpo teórico, Rosso, Dekas e Wrzesniewski (2010) elaboraram uma revisão do estado-da-arte do construto.

As tabelas a seguir expõem resumidamente o que os pesquisadores identificaram, nas pesquisas relacionadas ao tema, como as origens de significado e os mecanismos de significação do trabalho.

\begin{tabular}{|l|l|}
\hline Origens do significado do trabalho & Definição \\
\hline Self & $\begin{array}{l}\text { Faz referência ao "eu" do indivíduo como } \\
\text { principal vetor de comportamentos, atitudes e } \\
\text { crenças que influenciariam a maneira pela } \\
\text { qual o indivíduo atribui significado ao seu } \\
\text { trabalho. }\end{array}$ \\
\hline Outros & $\begin{array}{l}\text { Trata da relação com líderes, grupos e } \\
\text { comunidades e da família, como interfaces de } \\
\text { influência na dotação de sentido à experiência } \\
\text { profissional. }\end{array}$ \\
\hline
\end{tabular}




\begin{tabular}{|l|l|}
\hline Contexto & $\begin{array}{l}\text { Trata de fatores como o desenho do trabalho, } \\
\text { a missão organizacional, circunstâncias } \\
\text { financeiras do indivíduo, domínios não- } \\
\text { profissionais e a cultural nacional. }\end{array}$ \\
\hline Espiritualidade & Remete à uma força superior, um credo. \\
\hline
\end{tabular}

Tabela 1: Origens do Significado do Trabalho

Fonte: Rosso, Dekas e Wrzesniewski (2010).

\begin{tabular}{|l|l|}
\hline Mecanismo de significação & Definição \\
\hline Autenticidade & $\begin{array}{l}\text { Trata do alinhamento entre o comportamento } \\
\text { individual e as percepções do seu "verdadeiro" } \\
\text { eu. }\end{array}$ \\
\hline Autoeficácia & $\begin{array}{l}\text { Trata da certeza do indivíduo de sua } \\
\text { capacidade de agir de forma efetiva no seu } \\
\text { trabalho, a fim de cumprir com um } \\
\text { determinado objetivo. }\end{array}$ \\
\hline Autoestima & $\begin{array}{l}\text { Tem a ver com a capacidade de } \\
\text { autovalorização. }\end{array}$ \\
\hline Propósito & $\begin{array}{l}\text { Referente à ideia de intencionalidade das } \\
\text { ações individuais. }\end{array}$ \\
\hline Pertencimento & $\begin{array}{l}\text { Quando o indivíduo se vê motivado a manter- } \\
\text { se relacionado a outros indivíduos ou grupos. }\end{array}$ \\
\hline Transcendência & $\begin{array}{l}\text { Trata de uma conexão com algo "superior", } \\
\text { "maior que o eu"; tem a ver com abnegação, a } \\
\text { algo maior do que aspirações egocêntricas. }\end{array}$ \\
\hline Significação cultural e interpessoal & $\begin{array}{l}\text { Quando passa pelo viés da cultura e das } \\
\text { relações interpessoais. }\end{array}$ \\
\hline
\end{tabular}

Tabela 2: Mecanismos de Significação do Trabalho

Fonte: Rosso, Dekas e Wrzesniewski (2010).

Essa pesquisa, no entanto, tomará como base os postulados defendidos pelo Meaning of Work International Research Team (MOW, 1987). Os anos 1950 são tidos como o marco inicial dos estudos que tentam entender os mecanismos de significação do trabalho pelo indivíduo (MORIN, TONELLI e PLIOPAS, 2007). No entanto, é o trabalho realizado pelo MOW (1987), que é tido como uma referência na pesquisa sobre 0 tema, uma vez que trata do primeiro modelo teórico do construto, relacionando valores, crenças e expectativas que os empregados teriam em relação ao trabalho (PEREZGONZÁLEZ e VILELA, 2005).

No modelo final apresentado pela equipe de pesquisadores, o sentido do trabalho é composto por três 
dimensões, que são: a) centralidade do trabalho; b) normas sociais e c) objetivos e resultados valorizados do trabalho.

Por centralidade, os pesquisadores definem um conceito relacionado à importância. Isso faz referência a quão importante ou central, o trabalho é para o indivíduo.

Por normas sociais, os pesquisadores afirmam que os fenômenos que ocorrem no meio social do qual os indivíduos fazem parte podem influenciar a experiência profissional diretamente. Podem ser considerados como tais fenômenos: visibilidade de grupos considerados como "minoria" no mercado de trabalho, desenvolvimento tecnológico, mudanças na matriz econômica, dentre outros. Existem normas referentes aos direitos e aos deveres do indivíduo, não só para com a empresa, mas para com a sociedade como um todo.

Por objetivos e resultados, tem-se as motivações por trás do trabalho. Seja para a simples obtenção, ou tratando de aspectos mais subjetivos, relacionados a status e à sensação de pertencimento a um grupo específico (KUBO e GOUVÊA, 2011).

Tendo como base essa definição tridimensional do significado do trabalho, pretende-se aqui investigar de que maneira as investigações da Lava Jato, expondo publicamente a ocorrência da corrupção na Petrobras, afeta a percepção do trabalho na experiência profissional de funcionários da estatal.

\section{Aspectos Metodológicos}

A opção por uma pesquisa qualitativa destaca-se como a ideal para a resposta a esse tipo de questionamento. Nesse sentido, foram realizadas entrevistas em profundidade com sete funcionários da Petrobras, da rede de contatos do autor, locados na cidade do Rio de Janeiro. A idade média dos entrevistados foi de 32 anos e o tempo de empresa médio foi de aproximadamente 5 anos.

A tabela a seguir mostra em detalhes alguns dados demográficos do grupo selecionado.

\begin{tabular}{|l|l|l|l|l|l|}
\hline ID & Gênero & Idade & Formação & Cargo & $\begin{array}{l}\text { Tempo de } \\
\text { Empresa } \\
\text { (meses) }\end{array}$ \\
\hline 1 & F & 30 & $\begin{array}{l}\text { Administração } \\
\text { de Empresas }\end{array}$ & Pleno & 66 \\
\hline 2 & M & 30 & $\begin{array}{l}\text { Análise de } \\
\text { Sistemas }\end{array}$ & Júnior & 32 \\
\hline 3 & M & 29 & $\begin{array}{l}\text { Administração } \\
\text { de Empresas }\end{array}$ & Pleno & 54 \\
\hline 4 & F & 35 & $\begin{array}{l}\text { Administração } \\
\text { de Empresas }\end{array}$ & Pleno & 120 \\
\hline 5 & F & 35 & $\begin{array}{l}\text { Engenharia de } \\
\text { Produção }\end{array}$ & Pleno & 90 \\
\hline 6 & M & 33 & Economia & Júnior & 36 \\
\hline 7 & F & 32 & $\begin{array}{l}\text { Engenharia de } \\
\text { Produção }\end{array}$ & Júnior & 42 \\
\hline
\end{tabular}

Tabela 3: Perfil Demográfico dos Entrevistados

Fonte: Elaborado pelo autor. 


\section{SOBRE ORGULHO, VERGONHA E SUPERAÇÃO: O IMPACTO DA CORRUPÇÃO NA DOTAÇÃO DE SENTIDO AO TRABALHO ENTRE OS FUNCIONÁRIOS DA PETROBRAS}

No roteiro idealizado para essa pesquisa, constavam questões que tratavam das três dimensões do significado do trabalho propostas pelo Meaning of Work International Research Team (MOW, 1987): centralidade, normas sociais e resultados valorizados pelo trabalho. 0 sigilo sobre a identidade dos entrevistados foi garantido, que consentiram com a gravação em meio eletrônico de toda a conversa.

As transcrições serviram como base para a análise de conteúdo realizada a partir das declarações, a fim de cumprir com o objetivo do estudo.

\section{Resultados}

As entrevistas foram conduzidas de maneira a, inicialmente, coletar impressões gerais sobre a percepção dos funcionários do desenrolar das investigações da Lava Jato como um todo e, em seguida, aprofundar-se nas questões referentes às três dimensões do construto de significado do trabalho (MOW, 1987). Para encerrar, os entrevistados foram questionados de forma sucinta - e ao mesmo tempo genérica - sobre como davam sentido à experiência profissional na Petrobras, uma vez cientes dos casos de corrupção na empresa.

A fim de contemplar todos esses tópicos, esta seção será dividida em cinco partes. Uma vez que não foram identificados artigos científicos que tratassem da corrupção relacionada com aspectos subjetivos do trabalho, tal como a questão do significado, por exemplo, a articulação dos resultados com o referencial teórico apresentado anteriormente acaba bastante limitada. Vale reforçar que tal limitação evidencia 0 caráter exploratório deste trabalho e, de certa forma, ao mesmo tempo, ratifica a relevância teórica da pesquisa.

\section{Petrobras na Lava Jato: vergonha, impotência e culpa}

Questionados sobre a percepção do desenrolar das investigações da Lava Jato envolvendo a Petrobras, os empregados entrevistados declararam-se impotentes, envergonhados e culpados. 0 contraste entre um desempenho idealizado da Petrobras no imaginário coletivo e a realidade corrupta que vem sendo exposta causa a sensação de vergonha.

"Quando eu entrei na Petrobras ela era uma empresa promissora, sabe? As pessoas tinham orgulho de trabalhar na Petrobras... E hoje em dia eu acho que esse orgulho tá um pouquinho ferido. As pessoas não têm mais aquela coisa, sabe, de sair com crachá no peito... Já ouvi relatos de colegas que passaram por algumas situações desagradáveis por trabalhar na Petrobras. Tem gente que acha que todo mundo lá dentro é ladrão, então fazem algumas brincadeirinhas, algumas piadinhas que não cabem". - Entrevistado 1

"Acho que a palavra que define é "envergonhado". - Entrevistado 2

A questão da impotência se dá pelo fato de que as denúncias envolviam funcionários do topo da hierarquia organizacional, distantes da realidade cotidiana dos funcionários.

"Eles (a opinião pública) entendem que a Petrobras como um todo está envolvida. Então a gente é fortemente afetado pela opinião pública. Ela não necessariamente divide o que acontece com a alta liderança e com os funcionários, então, pessoalmente, até fora do ambiente de trabalho, a gente tem muito embate, pra se defender de uma coisa que a gente não está envolvido". - Entrevistado 4.

"Eu me sinto um pouco impotente, porque a gente não tem muito o que fazer. A gente só escuta pelas notícias. Muitas coisas a gente sabe antes pela mídia, do que pela própria empresa" - Entrevistado 1.

Inclusive, foi recorrente - principalmente entre os empregados da área de Auditoria - declarações sobre um sentimento de culpa, como que se a ocorrência das ações fraudulentas se desse em consequência de um desempenho insuficiente nessas funções.

"Então, hoje, pra mim, é como se fosse uma faca de dois gumes: ao mesmo tempo que eu acho uma coisa boa que esteja no Ministério Público, esteja em várias outras esferas aí pra ser investigada, é uma falha nossa, entendeu? A gente se sente meio culpado, por ter deixado passar alguma coisa, mas satisfeito por 
elas terem aparecido". - Entrevistado 3.

\section{Sobre a centralidade}

Kubo e Gouvêa (2012) explicam a dimensão da centralidade do construto do significado de trabalho do MOW (1987) como a importância dada pelo indivíduo ao seu trabalho. Dentre os funcionários da Petrobras consultados, os esquemas de corrupção apontados pela Lava Jato não causaram algum tipo de aumento ou redução da centralidade do trabalho.

"Não, isso não afeta não, de modo algum, porque o que vem acontecendo não desmerece e não tira a importância da minha missão, daquilo que foi designado a mim dentro da empresa". - Entrevistado 2.

Todavia, um certo desencantamento com a empresa começa a servir como um motivador na busca por diferentes opções de trabalho.

"Eu tinha uma visão muito boa do trabalho, tinha uma relevância muito grande, eu sentia um orgulho muito grande e estar lá, como auditor, e hoje menos. Hoje eu sinto que mal ou bem não era tudo aquilo que eu via". - Entrevistado 3.

"Não, eu acho que não. Eu acho que o trabalho continua tendo a mesma importância... Mas eu acho que depois de todo esse escândalo, eu acho que eu comecei a pensar mais em outros planos. Acho que por conta de todo esse movimento, de Lava Jato, de tudo mais, aumentou o medo da empresa - porque a empresa está reduzindo, está tendo uma reestrutura muito grande, isso tudo também teve a corrupção como uma causa muito forte, então a empresa está enxugando, está tendo plano de demissão incentivada, tá tendo reestruturação, gente perdendo cargo, empresas subsidiárias sendo vendidas... Então assim, acho que tudo isso acabou aparecendo mais depois que começaram as investigações da Lava Jato. Acho que tudo isso foi meio que consequência de toda essa corrupção que teve na empresa. $E$ por conta disso, as pessoas se sentem mais inseguras, como eu, e eu acho que é natural a gente vai buscando outras coisas". - Entrevistado 1.

\section{Sobre as normas sociais}

A partir das declarações dos funcionários da Petrobras entrevistados, percebe-se que a segunda dimensão do construto do significado de trabalho proposto pelo MOW (1987) foi a mais impactada pela percepção da corrupção. As normas sociais que orientam para os deveres (KUBO e GOUVÊA, 2012) do funcionário em relação à empresa e à sociedade tornaram-se mais sensíveis, intensificando a experiência profissional.

"Eu acho que depois da questão da Lava Jato, eu fiquei um pouco pior nesse sentido, porque eu me sinto na obrigação de hoje em dia de pegar um pouco mais profundamente em coisas que existem lá. Eu estou um pouco mais implacável, no sentido de não deixar que alguma coisa passe despercebida. Eu estou muito mais alerta das coisas que estão passando. Eu me sinto na obrigação de fazer mais do que eu sempre fiz. Eu sei que a minha percepção de trabalho mudou nesse sentido, de me sentir mais cobrado, tanto por mim, quanto pelas outras pessoas. Aumentaram (as cobranças). Eu me sinto mais cobrado hoje em dia, do que antes. A gente já sabe o que aconteceu e não era bom. Então, a forma como estava sendo feito antes era ruim, dava brechas pra várias coisas acontecerem". - Entrevistado 3.

"A gente teve que passar por um curso interno sobre acordos internacionais da ONU, sobre a conduta das pessoas que são signatárias do pacto global no mundo relacionado no meio empresarial. Tinham alguns itens lá que eu particularmente não sabia. Então, por esse tema estar mais acalorado, a gente dá mais atenção e isso influencia na minha vida, tanto na postura profissional, mas pessoal também. Existem normas internacionais, por exemplo, que nós não tínhamos conhecimento, não era um lugar comum pra nós e nós fomos obrigados a ser treinados, a começar a discutir a respeito disso. Assim a gente tomou conhecimento desses deveres que a gente tem também para com a sociedade como um todo". - Entrevistado 4.

Quanto às normais sociais orientadas para os direitos dos trabalhadores, os entrevistados não consideraram as investigações da Lava Jato como um fator de influência.

"Dos direitos em relação à empresa, não, eu não vi nenhuma diferença não. Acho que continua igual. Eu não acho que por conta disso eu tenha mais direitos do que eu normalmente tenho. Eu acho que essa 
corrupção foi um caso específico, um caso pontual, que um grupo de empregados atuou nisso e roubaram muito da empresa, mas que não é por conta disso que eu mereça mais". - Entrevistado 5.

"Quanto aos direitos, eu não acho. Talvez uma perda de alguns direitos, por uma pressão da sociedade. Por exemplo, uma PLR que não existiu, um abono que não existiu, por pressão da sociedade, porque estava previsto, mas isso pegaria muito mal perante a sociedade, então a Petrobras optou por não fazer alguns pagamentos... Mas não era exatamente um direito". - Entrevistado 7.

\section{Sobre os objetivos e resultados valorizados do trabalho}

Nesta dimensão, pouco também foi o impacto da percepção da corrupção na dotação de sentido à atividade profissional dentre os empregados da Petrobras entrevistados. Apesar de certo descontentamento com a empresa com o avanço das investigações, a motivação pelas questões "renda" e "estabilidade" mantiveramse firmes, mesmo após toda a exposição da Lava Jato.

"Não impactou, porque o meu principal objetivo de trabalhar na BR era a questão monetária, né?! Pela boa valorização do profissional que existe... Isso era a primeira coisa que pra mim fazia sentido. O meu objetivo era a questão monetária, até porque agora eu estou construindo uma família, então era uma questão mais financeira mesmo". - Entrevistado 3.

"Agora depois de toda essa exposição, eu ainda me sinto estável. Eu sinto como se eu ainda tivesse essa estabilidade na empresa. A motivação de ter feito concurso continua a mesma: estabilidade, fonte de renda e a possibilidade de trabalhar em coisas diferentes". - Entrevistado 1.

\section{Significado do trabalho na Petrobras pós-Lava Jato: o sonho continua, mas junto de um desafio}

Questionados sobre o significado do trabalho na Petrobras após a exposição das práticas corruptas da empresa pela operação Lava Jato, dentre o grupo de empregados consultados, é possível perceber que a ideia da carreira dos sonhos na estatal ainda existe. Todavia, esse raciocínio é acompanhado de uma ideia de desafio e superação.

"É a realização de um sonho. Sempre tive o sonho de participar do sistema Petrobras e trabalhar lá, não só pela questão financeira, é simplesmente a realização de um sonho. Na minha época, todo jovem tinha essa vontade, todo mundo tinha uma vontade de ser um funcionário Petrobras.. Então pra mim é a realização de um sonho mesmo". - Entrevistado 2.

"Acho que atualmente é um desafio. Eu me sinto um pouco responsável por reconquistar a credibilidade que a empresa tinha. Acho que isso vai acontecer, daqui a um tempo e eu me sinto um pouco parte disso, sabe?" - Entrevistado 1.

"Antes era um sonho entrar na Petrobras... E hoje em dia, pra mim, vai ser uma questão de superação. Eu vejo que não é uma coisa só minha. Todo mundo acredita na Petrobras. As pessoas sabem que aconteceram muitas coisas ruins, feita por poucas pessoas... O corpo funcional acredita muito na Petrobras. Esse é o meu significado: de início era um sonho e hoje em dia vai ser de superação. Vai não. Já estou sentindo que é esse caminho que é o correto pra gente seguir..." - Entrevistado 3.

Houve relatos que destacavam a intervenção da Petrobras no resgate da imagem que construiu ao longo dos tempos - da empresa "motivo de orgulho" para os brasileiros - que acabou bastante prejudicada com as denúncias de corrupção.

"Tem também uma grande intervenção da própria empresa, porque eles estão deixando claro que estão fazendo de tudo pra dar certo e a gente está aceitando essa visão da Petrobras que ela quer passar pra gente. E acho que daqui pra frente, o sentimento é de superação". - Entrevistado 6.

\section{Considerações finais}

A pesquisa cumpriu com o objetivo proposto, que foi o investigar de que maneira as denúncias de corrupção envolvendo a Petrobras impactam a dotação de sentido ao trabalho dentre seus empregados. Dentre 0 
grupo de funcionários entrevistados, a corrupção provoca consequências no significado do trabalho, tomando como referência o construto tridimensional proposto pelo MOW (1987).

Pelas declarações coletadas, percebe-se que a segunda dimensão do construto - a que trata das normas sociais, sobre direitos e deveres relacionados ao trabalho do indivíduo - foi impactada consideravelmente, principalmente no que se refere aos deveres dos profissionais para com a empresa e a sociedade. Através das ações de gestão de crise da Petrobras - que vão desde treinamentos relacionados à ética e a tratados internacionais anti-corrupção, até reposicionamentos estratégicos da comunicação - os funcionários tomaram para si a responsabilidade de contribuir para a reversão da crise e retorno aos "bons tempos" em que a Petrobras era sinônimo de orgulho, não só para os funcionários, mas para toda a sociedade brasileira. Tais ações merecem destaque pela relevância e eficiência numa situação de crise envolvendo corrupção.

As outras dimensões - centralidade e objetivos e resultados valorizados do trabalho - foram influenciadas em menor grau. Através dos relatos dos entrevistados, percebe-se que tal fato pode ser atribuído à boa reputação construída pela Petrobras ao longo dos seus 63 anos de existência. Consolidada como uma empresa pioneira, força motriz do desenvolvimento nacional e onde profissionais de diversas áreas podem conquistar a "carreira dos sonhos" - com estabilidade, bons salários benefícios diferenciados da média do mercado - as denúncias de corrupção pouco afetaram a centralidade e os objetivos e resultados valorizados do trabalho dos funcionários da Petrobras. Os funcionários, mesmo que de certa forma abalados, ainda se veem comprometidos com a empresa e vislumbram o fim da crise.

O caráter exploratório desse estudo, que articula a percepção da corrupção a aspectos subjetivos da experiência profissional, evidencia tanto limitações, quanto algumas oportunidades para pesquisas futuras. Um grupo mais diversificado de entrevistados, no que se refere ao tempo de empresa, pode gerar impressões diferenciadas sobre os efeitos da corrupção na significação do trabalho. Além disso, ferramentas quantitativas de mensuração do construto poderiam ser aplicadas a amostras representativas da população de funcionários da Petrobras, possibilitando generalizações estatisticamente confiáveis.

O impacto da corrupção em subjetividades relacionadas ao trabalho junto a funcionários de empresas privadas envolvidas na Operação Lava Jato também merece ser investigado cientificamente. Empregados de organizações que não gozem de uma reputação tão sólida quanto a da Petrobras, não apenas perante o seu quadro funcional, mas à sociedade brasileira como um todo, provavelmente perceberiam de maneira diferente esse tipo de crise, tendo a questão do significado do trabalho influenciada de outra forma.

\section{Referências Bibliográficas}

Baumeister, R. F. (1991). Work, work, work, work. In Meanings of Life (pp. 116-144). New York: The Guilford Press.

Brei, Z. (1996a). Corrupção: dificuldades para definição e para um consenso. Revista de Administração Pública, v. 30, n. 1, p. 64-77.

Brei, Z (1996b). A corrupção: causas, consequências e soluções para o problema. Revista de Administração Pública, v. 30, n. 3, p. 103-115.

Brief, A. P., \& Nord, W. R. (1990). Meanings of occupational work. Lexington: Lexington Books.

Carvalho, A. (2009). The effect of institutions on the external financing of the Brazilian firms. Revista Brasileira de Finanças, v. 7, n. 1, p. 1-27.

Cavalheiro, G. (2010). Sentidos atribuídos ao trabalho por profissionais afastados do ambiente laboral em decorrência de depressão. Dissertação apresentada à Universidade Federal de Santa Catarina, Florianópolis, SC.

Costa, L. (2008). Combatendo a corrupção através de códigos de CRS em mercados emergentes: indústria de petróleo e gás natural. RAE-eletrônica, v. 7, n. 1, p. 1-19.

Kubo, S., Gouvêa, M. (2011). Análise de fatores associados ao significado do trabalho. Revista de Administração, v.47, n.4, p.540-554, out./nov./dez. 
Meaning of Work International Research Team. (1987). The meaning of working. London: Academic Press. Miari, R., Mesquisa, J., Pardini, D. (2015). Eficiência de Mercado e Corrupção Organizacional: Estudo dos Impactos Sobre o Valor dos Acionistas. Brazilian Business Review, v. 12, n. Ed. Especial, p. 1-26.

Morin, E., Tonelli, M. J. Pliopas, A. (2007). Trabalho e seus sentidos. Psicologia \& Sociedade. 19, Edição Especial 1: 47-56.

Oliveira, R. (2006). Contabilidade, Controle Interno e Controle Externo: trinômio necessário para combater a corrupção. Pensar Contábil, v. 8, n. 31, p. 1-9.

Pérezgonzález, J., Vilela, L. (2005). La centralidade Del trabajo. Dublin: Lulu.

Rausch, R., Soares, M. (2010). Controle social na administração pública: a importância da Transparência das Contas Públicas para inibir a corrupção. Revista de Educação e Pesquisa em Contabilidade, v. 4, n. 3, p. 23-43.

Rosso, B., Deka, K., Wrzesniewski. A. (2010) On the meaning of work: A theoretical integration and review. Research in Organizational Behavior. 30. 91-127

Silva, A., Braga, E., Laurencel, L. (2009). A corrupção em uma abordagem econômico-contábil e o auxílio da auditoria como ferramenta de combate. Contabilidade Vista \& Revista, v. 20, n. 1, p. 95-117.

Silva, M. (1994). Corrupção: Tentativa de uma definição funcional. Revista de Administração Pública, v. 28 , n. 1, p. 18-23.

Silva, M. (1999). The political economy of corruption in Brazil. Revista de Administração de Empresas, v. 39 , n. 3, p. 26-41.

Super, D. E., \&Sverko, B. (1995). Life roles, values, and careers. San Francisco: Jossey-Bass.

Tolfo, S. da R., Coutinho, M. C., Baasch, D. \& Cugnier,J. S. (2011). Sentidos y significados deltrabajo: unanálisiscon base en diferentes perspectivas teórico-epistemológicas em Psicología. Universitas Psychologica, 10(1), 175-188.

Tolfo S.; Grandi, C.; Althof, D.; Picinin, D.; Noermberg, T. (2005) O processo de reestruturação produtiva de uma empresa de telecomunicações: 0 caso dos trabalhadores remanescentes, demitidos e que aderiram ao PDI. EnANPAD 2005, Porto Alegre, v. 29, p. 473.

Tolfo, S., Piccinini, V. (2007). Sentidos e significados do trabalho: Explorando conceitos, variáveis e estudos empíricos. Psicologia \& Sociedade, 19, Edição Especial 1: 38-46.

Vaz, J., Rocha, V. (2005). Imagem das instituições públicas brasileiras: a utilização da promoção como ferramenta para evitar sua deterioração. Revista Gestão \& Planejamento. Salvador, v. 1, n. 12, p. 53-70.

Wrzesniewski, A. (2003). Finding positive meaning in work. In K. S. Cameron, J. E. Dutton, \& R. E. Quinn (Eds.), Positive organizational scholarship. San Francisco: Berrett-Koehler Publishers, Inc.

Zuccolotto, R., Teixeira, M. (2014). A efetividade dos institutos supremos de auditoria e dos legislativos na transparência fiscal. Revista de Contabilidade e Organizações, v. 8, n. 22, p. 26-38. 